\title{
Oldest known ant fossils discovered
}

Lere we report fossil ants, including a new genus of Ponerinae, about 50 million years (Myr) older than the previous oldest specimens. These discoveries in amber from the Turonian stage (92 Myr ago) of New Jersey in the United States have important implications for estimates dating the origin of ants, and extend the age of an extant ant subfamily back about 50 Myr.

Until now, a specimen of Sphecomyrma freyi in a piece of amber from Cliffwood Beach, New Jersey, was one of the few noncompression fossil ants from the Cretaceous period showing most morphological details ${ }^{1}$. The metapleural gland is the only morphological trait unique within the Hymenoptera that distinguishes ants, and can be seen in most ants embedded in amber. This gland produces antibiotic-like substances ${ }^{2}$, necessary to maintain nests underground or in humid pieces of wood, where bacteria and fungi would otherwise invade immobile broods. The gland is seen in modern species, opening above the hind coxae. Development of the gland and eusociality were probably correlated and are involved in the great ecological success of the ants. In an Amazonian rainforest, for example, ants make up more than $25 \%$ of the total animal biomass ${ }^{3}$.

Wilson et al. ${ }^{1}$ described an almost perfectly preserved worker of $S$. freyi, but the debate remained whether this fossil is an ant because the presence of the metapleural gland was uncertain. Sphecomyrma was thus excluded from a recent phylogenetic analysis of the Formicidae ${ }^{4}$, and its relatively short first antennal segment in workers was assumed to prevent the basic social behaviour of trophallaxis ${ }^{5}$.

Our new specimens include three worker and four male ants. One complete, wellpreserved worker was the second discovery of S. freyi. Among other well-preserved traits in this specimen are the external and even part of the internal anatomy of the metapleural gland. The gland has a circular opening and a very large subcuticular atrium (Fig. 1a). Sphecomyrma is thus an ant.

Two of the males are a new species of the Cretaceous genus Baikuris, known previously only from Upper Cretaceous (Santonian) amber from Taymyr, northern Siberia. The
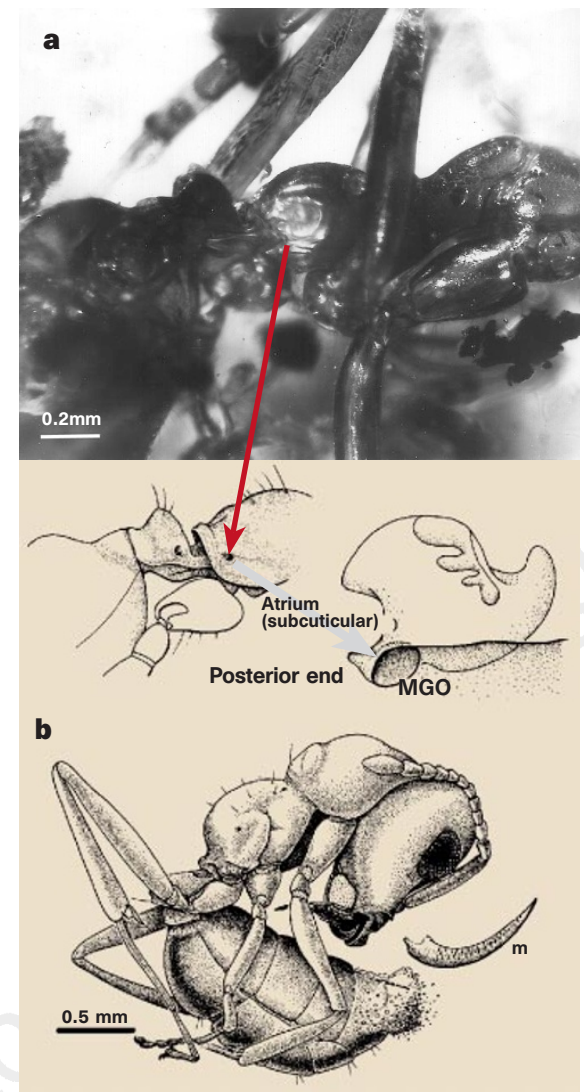

Figure 1 Photomicrographs of New Jersey ant fossils. a, Alitrunk and portion of the gaster of the new $S$. freyi worker with a drawing showing the position and structure of its metapleural gland (MGO). b, Lateral view of the new Cretaceous ponerine genus ( $m$, mandible in frontal view). A detailed description will be provided elsewhere $^{6}$ (http://research.amnh.org/entomology/social_insects).

third male belongs to a genus as yet undetermined. The fourth male is tentatively assigned to Sphecomyrma and would be the first known male of that genus.

Another worker represents a new genus, distinguished by its clubbed antennae, proportions of the antennal articles, thin mandibles that lack teeth and cross extensively when closed, and a girdling constriction of the gaster typical of the large modern subfamily, the Ponerinae (Fig. 1b). Furthermore, the broad attachment of the third and fourth abdominal segments, and the apical denticles on the genae, indicate a relationship with ants of the ponerine tribe Amblyoponini.

Addition of these two new taxa confirms the basal position of Sphecomyrma ${ }^{6}$, but as part of a quadritomy. The position of the new ponerine within one clade of the Ponerinae demonstrates that one major lineage of extant ants was established well before the formation of amber from Sakhalin Island (probably Palaeocene) ${ }^{7}$ and of Eocene Baltic amber $^{8}$, which are about 50 Myr younger than the New Jersey amber.

A reasonable estimate would thus place the origin of the ants into the lowermost Cretaceous (about 130 Myr ago), but probably no older. This conclusion is consistent with the relationship of the Formicidae to the wasp families Vespidae and Scoliidae ${ }^{9}$ and the phylogenetic position of the Cretaceous Vespidae ${ }^{10}$. On this basis, a hypothesis of a Lower Jurassic origin of ants ${ }^{11}$, based on estimated divergence time of mitochondrial cytochrome $b$ sequences, is unlikely.

Although ants originated in the Cretaceous, it was not until the Tertiary $^{7}$ period that they became so dominant and diverse in terrestrial ecosystems, as documented in Baltic $^{8}$ and Dominican amber ${ }^{12}$. We are still examining why the radiations were delayed until the Tertiary.

Donat Agosti, David Grimaldi,

James M. Carpenter

Department of Entomology, American Museum of Natural History, Central Park West at 79th Street,

New York, New York 10024-5192, USA

e-mail: agosti@amnh.org

1. Wilson, E. O., Carpenter, F. M. \& Brown, W. L. Jr. Psyche 74, 1-19 (1967).

2. Beattie, A. J., Turnbull, C. L., Hough, T. \& Knox, R. B. Ann. Entomol. Soc. Am. 79, 448-450.

3. Fittkau, E. J. \& Klinge, H. Biotropica 5, 2-14 (1973).

4. Baroni Urbani, C., Bolton, B. \& Ward, P. S. Syst. Entomol. 17, 301-329 (1992).

5. Dlussky, G. M. Paleont. J. 1983 (3), 65-78 (1983).

6. Grimaldi, D. et al. J.M. Am. Mus. Novit. (in the press).

7. Dlussky, G. M. Paleont. J. 1988 (1), 50-61 (1988).

8. Wheeler, W. M. Schr. Phys.-Ökon. Ges. Königsb. 55, 1-142 (1915). 9. Brothers, D. J. \& Carpenter, J. M. J. Hymenopt. Res. 2, 227-304 (1993).

10. Carpenter, J. M. \& Rasnitsyn, A. P. Psyche 97, 1-20 (1990). 11. Crozier, R., Jermiin, L. S. \& Chiotis, M. Naturwissenschaften 84, 22-23 (1997).

12. Hölldobler, B. \& Wilson, E. O. The Ants (Harvard Univ. Press, Boston, 1990).

\section{Climate change and}

\section{Australian wheat yield}

Nicholls $^{1}$ reported that $30-50 \%$ of the increase in Australian wheat yields in the period 1952-92 resulted from climate change. He estimated a simple linear rela- tionship where a $1^{\circ} \mathrm{C}$ fall in diurnal temperature range increased Australian wheat yield by $0.52 \mathrm{t} \mathrm{ha}^{-1}$. This effect, taken with the trend in diurnal range, accounted for $45 \%$ of the yield increase between 1952 and 1992. In an extended model with three climate variables, Nicholls found that changes in minimum temperature had had most impact on wheat yield and that rainfall change had con- tributed little. In our view, Nicholls's results need qualification and should be interpreted with caution. They are only estimates, and do not include standard errors to indicate their precision.

The analytical challenge is to separate the effects of climate change from other factors affecting Australian wheat yields. Nonclimate factors include total wheat area, the 
location of Australia's wheat plantings, previous soil cropping history, management, technology and the levels of conventional inputs. Nicholls did not use data on non-climate factors, which he proxied by a linear trend in yields. Simple statistical procedures for removing trend effects include adding a trend variable to relationships between series, or working with first differences of the series. The procedures are not equivalent. The choice is not arbitrary but relates to whether the trends are deterministic or stochastic.

Nicholls did consider deterministic climate trends, the extent of which, together with the estimated effects of climate change on yield, provided his estimates of the contribution of climate change to wheat yield increases. But he 'detrended' using first differences, an approach more appropriate to stochastic trends. Differencing is consistent with deterministic trends if a yield-trend effect is included as an intercept in the relationship between the first differences of yields and climate variables. Unless yields have a random-walk component, the error term in the relationship between first differences would be correlated with the first differences of the climate variables, as the errors include a model-misspecification component. Ordinary least-squares estimates of the difference relationship would thus be biased. Nicholls both forced the intercept to be zero and used ordinary least-squares.

Improvements in wheat varieties and farming systems from 1952 to 1992 enabled wheat producers to cope better with weather conditions by use of larger machinery, 'knockdown' herbicides, increased and better fertilizers, changes in crop rotations, and more drought-tolerant varieties. Location of wheat production also moved significantly towards 'new', drier, more 'open' land. Yield responses to non-climate factors are probably non-linear. They are also likely to depend on climate, and vice versa. Such interactions should be recognized by including interaction variables in yield models. When omitted, such effects must become part of the error term, be picked up by the trend effect, or become part of the estimated climate effect. As interaction variables tend to correlate with climate changes, their omission would probably bias the estimated climate effects.

Even without interactions, estimated climate effects might be biased. Nicholls noted the possibility of confounding climate and non-climate effects where these factors are correlated, and that farmers might alter inputs in response to seasonal conditions. Farmers can adjust fertilizer applications, timing and extent of plantings, pesticide use, and both management and harvest effort. First differences of climate variables are then likely to be correlated with variations in these inputs, and estimated climate effects con- founded with the effects of these inputs. In Nicholls's data, yield might be better modelled by diurnal range, trend and a diurnal range-trend interaction than without the interaction term. Yield change is thus a function of variables other than change in diurnal range.

\section{David Godden, Robert Batterham,}

\section{Ross Drynan}

Department of Agricultural Economics,

University of Sydney, NSW 2006, Australia e-mail:d.godden@agec.usyd.edu.au

We believe that Nicholls's conclusion ${ }^{1}$ - that reduced frost frequency has been predominantly responsible for $30-50 \%$ of the $45 \%$ increase in average Australian wheat yield between 1952 and 1992 - is not correct.

Nicholls correlated the year-to-year differences in average wheat yield from the cropping zones, which comprise less than $10 \%$ of the Australian land area, with yearto-year differences in annual precipitation, and maximum and minimum temperatures averaged across the continental area. Wheat is grown only over the winter/spring period within a small fraction of that climatic range. Additionally, since 1952 the range of wheat production has extended substantially northwards in eastern Australia and expanded greatly in Western Australia.

Assuming that the correlations between year-to-year differences in national average yield and weather variables would apply also to decadal changes, Nicholls attributed almost half of the increase in national average yield over four decades to a reduction in diurnal temperature range. Further analysis of partial correlation coefficients attributed no causation to rainfall and emphasized a strong underlying relationship with average minimum temperature. Low availability of soil water, however, might still explain low yields if a correlation exists between minimum temperature and low rainfall in Australian wheat-growing zones.

Rimmington and Nicholls ${ }^{2}$ have shown low correlations between the Southern Oscillation Index and wheat yield in southern Australian states but better correlations for Queensland, New South Wales and Western Australia, as well as an overall significant correlation for the continent, which these authors attributed to rainfall. Thus, by explaining reduced wheat yields by decreased frost incidence, Nicholls might have incorrectly attributed causality to correlation. Drought years in the wheat districts tend to be less cloudy and have lower minimum temperatures.

We think that a correlation of yield with annually averaged minimum temperature is unlikely to be closely related to frost effects. Yield is damaged by frost only during the flowering period of a few days. Australian cereal growers have traditionally been very concerned about frosts, preferring late-flow- ering varieties and planting dates that give near-certain frost-avoidance, thereby losing yield in most years through end-of-season drought. Thus it is unlikely that the scale of yield loss from frost 40-50 years ago was sufficient to give scope for a $10-20 \%$ increase through less frost damage.

The 10-year period from 1983, when the national average yield was higher than it had been over the level trend-line of the previous 30 years (see Fig. 1 of ref. 1), was characterized not only by warming but also by new technologies. These included the almost complete adoption of high-yielding semidwarf wheat varieties, greater use of nitrogen fertilizer, better crop rotations (especially in areas where yields have increased most, capitalizing on earlier planting opportunities made possible by new herbicide and tillage practices), the adoption of winter varieties enabling earlier planting, and the use of earlier-flowering wheats that specifically shifted the balance towards more frost risk and less drought effect. Although it is conceivable that decreasing spring frost frequency for northeast Australia ${ }^{3}$ has helped the latter strategy, we think it could not have been directly responsible for as much as $10-20 \%$ of the yield difference before and after 1982.

The national rainfall increase from 1952 to 1992 of $39 \mathrm{~mm}$ (ref. 4) could be agriculturally significant. If, for example, it applied to the wheat areas and fell entirely during the growing season it could account for the yield increase observed. But an analysis of rainfall trends in wheat-growing areas since 1952 (ref. 4) reveals a slight decrease in growing season rainfall, rather than an increase. National and, more importantly, regional correlations between rainfall and wheat yield ${ }^{1}$ show clearly that the analysis needs to be made more specific to the wheat-growing season and wheat regions. It has also been shown $^{5}$ that the observed yield increases have not occurred uniformly but patchily in already high-yielding regions, and despite yield decreases in some areas producing lower yields.

A multiple regression of absolute yield on climatic variables is more straightforward than the 'first-difference' approach of Nicholls ${ }^{1}$ because the correlation between yields of consecutive years seems to be small whereas there is an inherently stronger correlation between consecutive first-differences. Hence it is more difficult to specify reliability for the estimates of the effects of climate change.

The first-difference approach also biases against influences with low short-term variability relative to long-term change such as change in atmospheric $\mathrm{CO}_{2}$ concentration. Unlike inter-annual differences in temperature and rainfall, the effects on yield of the small monotonic annual increase in $\mathrm{CO}_{2}$ concentration are cumulative, but their 